\section{Star quality}

Japan's Nobel

laureates have a

celebrity status that

outstrips anything seen

by their contemporaries

in North America or

Europe. How have they

balanced the desire to

be a positive influence

with the need to retain

some privacy? David

Cyranoski finds out.

$\mathrm{S}$ ome three decades after sharing the Nobel Prize in Physics for his work on tunnelling by electrons in semiconductors, Leona Esaki is still a hot property. Caught after giving a talk in Tokyo in 2000, he politely declined Nature's request for an interview. "Maybe in a couple of months," he apologized. "I'm just too busy." A gruelling schedule of lectures and social engagements, combined with his role as president of the Shibaura Institute of Technology, left him with precious little spare time. "It's the duty of a Nobel laureate in Japan," Esaki explained.

At least today, there are a few others to share that duty. Between 2000 and 2002, four Japanese scientists received Nobel prizes just one less than the country's researchers gained over the previous century. Remarkably, this followed hard on the heels of an official government target to win 30 Nobel prizes over the next 50 years (see Nature 413, 560-564;2001).

It seems unlikely that there's a direct connection, but the wave of recognition from Stockholm has resulted in a frenzy of media interest. The four new laureates are household names, and the Japanese public can't seem to learn enough about their personal lives - their hobbies, dietary preferences and even family life have become fodder for magazine articles and television programmes.

The tide of enthusiasm has been a mixed blessing, the scientists say. The Nobel awards gave a much-needed boost to a nation that was engaged in a bout of soul-searching in the midst of an extended economic recession. More specifically, scientists believe that the publicity has helped to protect research budgets from cuts, and has reignited interest among students who had seemed increas-

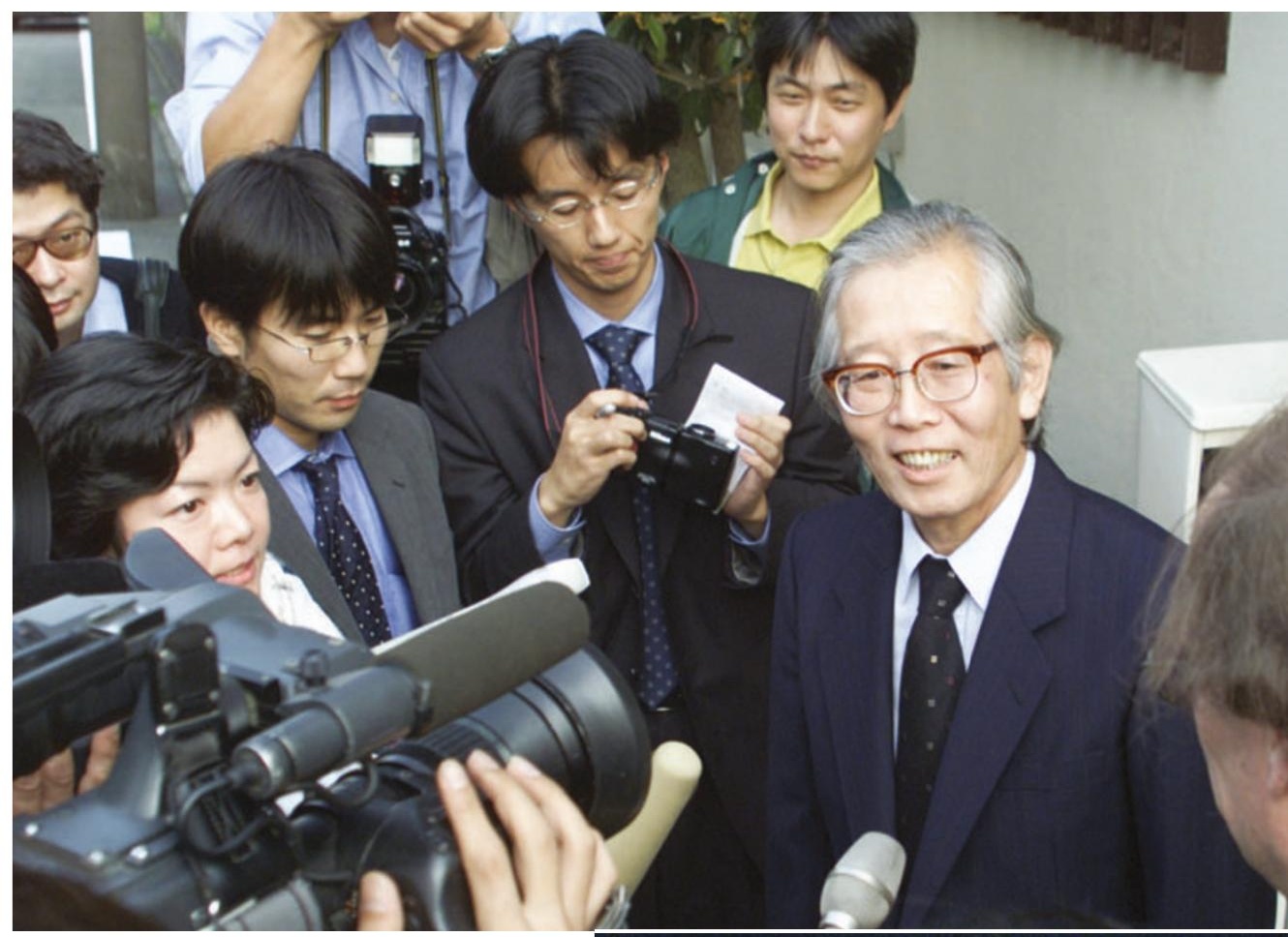

Eye of the storm: Japan's four recent Nobel laureates (clockwise from above) Hideki

Shirakawa, Ryoji Noyori, Koichi Tanaka and Masatoshi Koshiba have become the centre of media attention since their awards.

ingly averse to taking courses in the sciences. "Overall, it has been very positive," says Ryoji Noyori of Nagoya University, who shared the 2001 chemistry prize for developing a method to preferentially produce molecules whose structures have either left- or righthanded orientations. But when researchers start to be treated as entertainers, he warns, there is a price to pay. "That kind of treatment may spoil the image of science."

\section{Feeding frenzy}

The four recent Nobellists were ill-prepared for a whirlwind of media interest that often crossed the line into pure entertainment. One New Year's TV special in 2003 featured Masatoshi Koshiba of the University of Tokyo - who shared the 2002 physics prize for confirming the existence of elusive subatomic particles called neutrinos — and his wife. The show was billed as tackling Koshiba's "hardships, his surprising favourite dishes, and what he's like around the house". Such excursions into Koshiba's private life had by then become commonplace. "There were so many programmes that I was on, I don't remember which one you are talking about," he says.

Koichi Tanaka of the Shimadzu Corporation in Kyoto, who shared the 2002 chemistry prize for developing a mass-spectrometry method to study large biological molecules, had much the same experience. "They wanted to know everything about how I lived and what I normally ate," he says. "Nobel winners

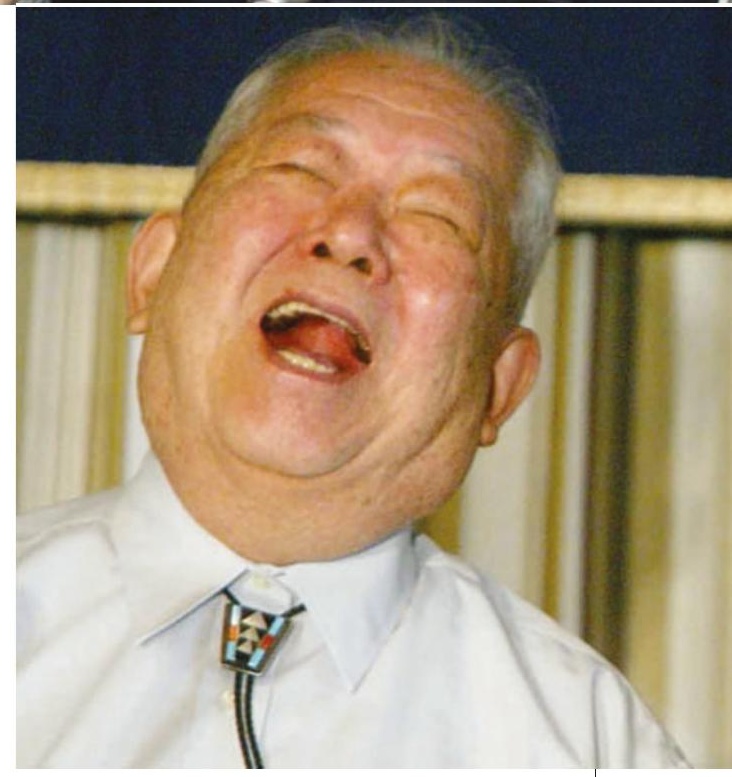

are celebrated like sports stars, like they are a completely different type of person."

Even within this small band of celebrities, Tanaka became a particular favourite of TV producers and magazine editors. A previously unknown industrial scientist, he was presented as a model of endeavour and modesty - a down-to-earth star in a world of flashy celebrities. In December 2002, for example, a popular weekly magazine latched on to the rumour that Tanaka met his wife through the omiai system — a traditional arrangement in which a mediator brings couples together. The article documented the regrets of women who had passed up the 'Tanaka-type' male on the omiai scene. If such men's charms were appreciated, it suggested, more successful marriages would result.

The cult of celebrity that surrounds Nobel laureates in Japan isn't restricted to 
